\title{
MICROSTRUCTURE AND MECHANICAL PROPERTIES OF THE Mg-Zn-Ca AND Mg-Zn-Ca-Mn BIODEGRADABLE MAGNESIUM ALLOYS AFTER HOT EXTRUSION
}

\author{
${ }^{1}$ Viacheslav BAZHENOV, ${ }^{2}$ Anna LI, ${ }^{1}$ Andrey KOLTYGIN, ${ }^{2}$ Alexander KOMISSAROV, \\ ${ }^{1}$ Stanislav TAVOLZHANSKII, ${ }^{2}$ Denis TEN, ${ }^{3}$ Yury GAMIN, ${ }^{2}$ Julia KOMISSAROVA \\ ${ }^{1}$ National University of Science and Technology, Foundry Department, Moscow, Russian Federation, \\ v.e.bagenov@gmail.com \\ ${ }^{2}$ National University of Science and Technology, Laboratory of Hybrid Nanostructured Materials, Moscow, \\ Russian Federation, anna23-95@mail.ru \\ ${ }^{3}$ National University of Science and Technology, Department of metal forming, Moscow, Russian Federation, \\ gamin910@gmail.com
}

https://doi.org/10.37904/metal.2019.757

\begin{abstract}
Biodegradable implants are effective because of no revision surgery is needed for further implant removing. It was known that the Mg-Zn-Ca-(Mn) alloys are promising for biodegradable applications because of high biocompatibility and enough mechanical properties. The influence of hot extrusion at different temperatures on the microstructure and mechanical properties in longitudinal and transverse direction with respect to the deformation axis of four $\mathrm{Mg}-\mathrm{Zn}-\mathrm{Ca}-(\mathrm{Mn})$ alloys was studied in this research. It was established that for low hot extrusion temperatures the large non-recrystallized elongated grains surrounded by fine grains are typical. With increasing of hot extrusion temperature, the fully recrystallized fine uniform grains were observed. The grain size after extrusion change from 1.5 to $6.2 \mu \mathrm{m}$ and the upper limit relates to hot extrusion at high temperatures. It was demonstrated that higher ultimate tensile strength, higher yield strength and lower elongation is typical for low hot extrusion temperatures and vice versa. The mechanical properties are higher in longitudinal direction and the best its combination was observed for MgZn4Ca0.5 alloy.
\end{abstract}

Keywords: Biodegradable magnesium alloys, Mg-Zn-Ca-Mn, Mg-Zn-Ca, hot extrusion, grain size

\section{INTRODUCTION}

The density and Young modulus of magnesium alloys are close to those of cortical bone [1,2]. Therefore, these alloys were used as materials for producing of biodegradable implants [2]. The $\mathrm{Mg}-\mathrm{Zn}-\mathrm{Ca}$ alloys are promising for biodegradable applications in view of high biocompatibility [3]. In previous works shown that after hot extrusion or equal channel angular pressing (ECAP) these alloys have high mechanical properties [3-8]. Also, the $\mathrm{Mn}$ addition was used for grain refinement and for corrosion resistance improvement $[6,9,10]$.

The goal of this work was to investigate the microstructure and mechanical properties of $\mathrm{Mg}-\mathrm{Zn}-\mathrm{Ca}$ and $\mathrm{Mg}$ $\mathrm{Zn}-\mathrm{Ca}-\mathrm{Mn}$ alloys after hot extrusion at different temperatures.

\section{MATERIALS AND METHODS}

The commercial purity magnesium (99.9 wt\% Mg), zinc (99.98 wt\% Zn) and Mg-30 wt\% Ca and Mg-2.7 wt\% $\mathrm{Mn}$ master alloys were used as raw materials for alloys preparation. Melting was carried out in induction furnace under cover of carnallite flux for melt protection. The low-alloy steel crucible was used. For hot extrusion processing the $60 \mathrm{~mm}$ diameter ingots were casted into aluminum permanent mold. The chemical composition of alloys is presented in Table 1. Because of in each melt only two ingots were casted and for each alloy melting was done twice, in table 1 the alloys composition range was presented. The ingots were heat treated during 6 hours at $350^{\circ} \mathrm{C}$ for stress relieving. 
Table 1 Chemical composition of alloys (in wt\%)

\begin{tabular}{|c|c|c|c|c|}
\hline Alloy & Mg & Zn & Ca & Mn \\
\hline MgZn2Ca0.5 & Bal. & $2.1-2.4$ & $0.4-0.7$ & - \\
\hline MgZn4Ca0.5 & Bal. & $3.6-4.1$ & $0.4-0.7$ & - \\
\hline MgZn2Mn1Ca0.5 & Bal. & $2.1-2.2$ & $0.4-0.6$ & $0.8-1.0$ \\
\hline MgZn4Mn1Ca0.5 & Bal. & $3.7-3.9$ & $0.3-0.5$ & $0.9-1.0$ \\
\hline
\end{tabular}

The ingots were machined to cylindrical-shaped billets for hot extrusion with the height of $145 \mathrm{~mm}$ and the diameter of $50 \mathrm{~mm}$. Before the hot extrusion, the billet and die preheated to $200-300{ }^{\circ} \mathrm{C}$. The hot extrusion was performed using the direct extrusion method under the ram speed of $2 \mathrm{~mm} / \mathrm{s}$ and the extrusion ratio of 6 . Finally, cylindrical bars with the diameter of $20 \mathrm{~mm}$ and the length of $\sim 1 \mathrm{~m}$ were obtained.

The Tescan Vega SBH3 Scanning Electron Microscope with EDS system Oxford and Carl Zeiss Axio Observer.D1m optical microscope for microstructure analysis were used. For revealing of grains, the etchant with the following composition: $11 \mathrm{~g}$, picric acid; $11 \mathrm{ml}$, acetic acid; and $100 \mathrm{ml}$, ethanol was used. Grain size was measured by linear intercept method. The alloys chemical composition was determined by EDS analysis in metallographic sections with area of $1 \mathrm{~mm}^{2}$. For each sample three areas were analyzed, and mean elements content was calculated. Microstructure observation was done in longitudinal and transverse sections of extruded bars.

For mechanical testing the samples with $1.2 \times 1.2 \mathrm{~mm}$ cross section and $12 \mathrm{~mm}$ length were spark machined from extruded bars. The samples were cut in longitudinal and transverse direction (parallel and perpendicular to rolling direction respectively). Tensile tests were performed on the INSTRON 5569 universal testing machine.

\section{RESULTS AND DISCUSSION}

The microstructures of $\mathrm{MgZn2Ca0.5,} \mathrm{MgZn4Ca0.5} \mathrm{and} \mathrm{MgZn2Mn1Ca0.5} \mathrm{alloys} \mathrm{hot} \mathrm{extruded} \mathrm{at} \mathrm{different}$ temperatures are presented in Figure 1. Both microstructures in longitudinal and transverse directions are shown. The extrusion direction is shown by black arrow in longitudinal microstructure. It can be seen that in alloys microstructures at longitudinal direction the elongated $\mathrm{Ca}_{2} \mathrm{Mg}_{6} \mathrm{Zn}_{3}$ phase (dark in photographs) is observed. Also, for $\mathrm{MgZn} 4 \mathrm{Ca} 0.5$ alloy the amount of $\mathrm{Ca}_{2} \mathrm{Mg}_{6} \mathrm{Zn}_{3}$ phase is higher than for other alloys. It is important to note that for extrusion at lower temperatures the grain size is smaller, but in this case the ratio of non-recrystallized large elongated grains is higher. At higher hot extrusion temperatures, the more uniform distribution of grain size is observed.

The alloys grain size vs extrusion temperature shown on Figure 2. Firstly, we can see that grain size is decreased with decreasing of hot extrusion temperature. The exception is $\mathrm{MgZn} 4 \mathrm{Ca} 0.5 \mathrm{Mn} 1$ alloy where the grain size is near $3 \mu \mathrm{m}$ at all extrusion temperatures. For MgZn2Ca0.5Mn1 alloy the difference in grain size after extrusion at lowest and highest temperatures is lower than for MgZn2Ca0.5 and MgZn4Ca0.5 alloys. As for alloys without $\mathrm{Mn}$ addition, the grain size for $\mathrm{MgZn} 2 \mathrm{Ca0} .5$ alloy at extrusion temperature $200{ }^{\circ} \mathrm{C}$ was 1.5 $\mu \mathrm{m}$ and at extrusion temperature $300^{\circ} \mathrm{C}$ the grain size was $6.2 \mu \mathrm{m}$ respectively.

The tensile properties vs extrusion temperature of the alloys after hot extrusion are shown in Figure 3. It can be seen that ultimate tensile strength (UTS) for most of alloys and extrusion temperatures (Figure 3a) in longitudinal direction is higher than in transverse direction. Only for MgZn2Ca0.5 and MgZn4Ca0.5 alloys the UST is nearly the same in longitudinal and transverse directions at extrusion temperature of $300^{\circ} \mathrm{C}$. As for influence of extrusion temperature on UTS it can be said that the UTS in longitudinal direction is increased with decreasing of extrusion temperature, but for UTS in transverse directions no correlation with extrusion 
temperature is observed. The UTS in longitudinal direction is nearly the same for all of alloys compositions at the same extrusion temperatures and the $\mathrm{Zn}$ and $\mathrm{Mn}$ contents have no influence on this property.

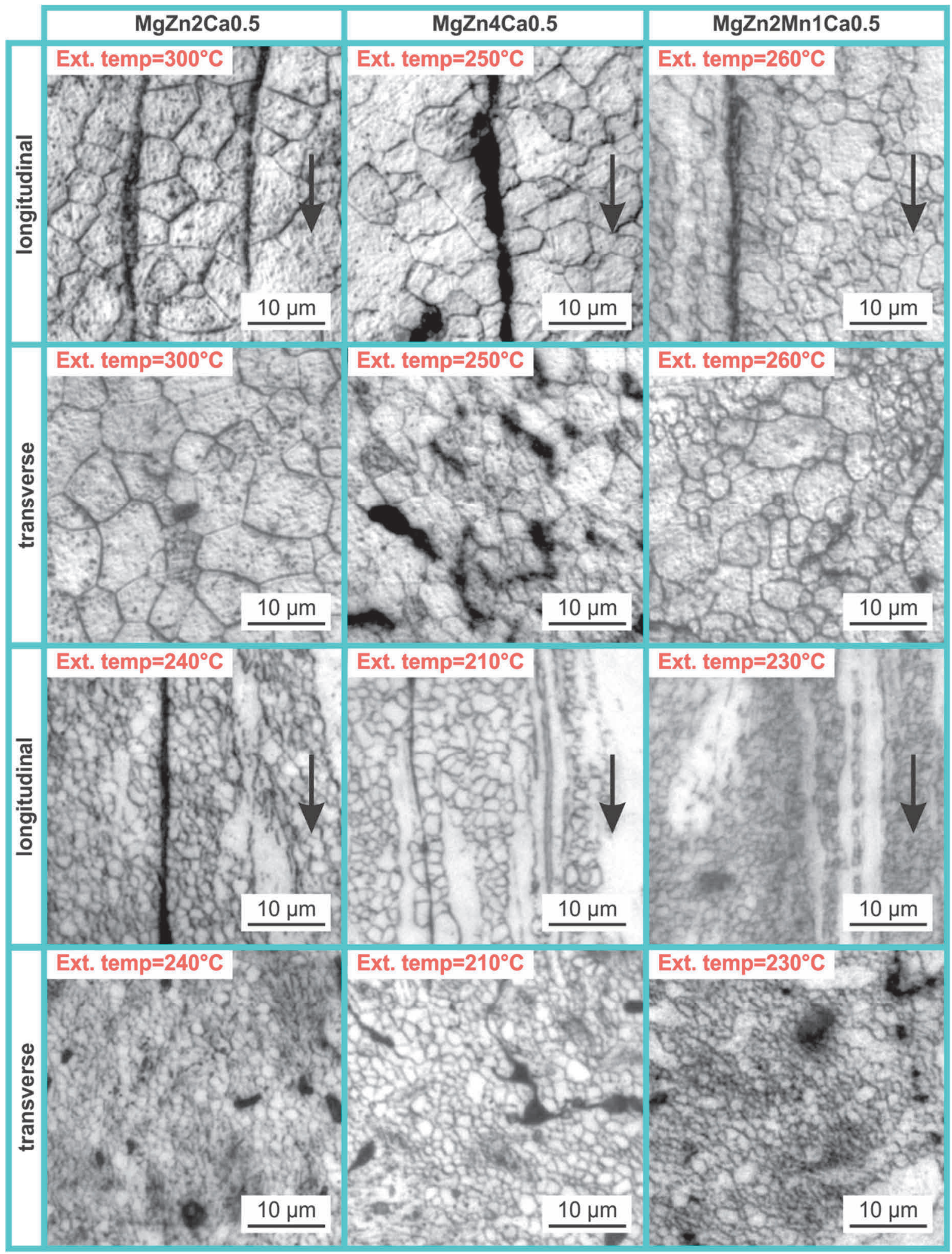

Figure 1 The microstructure of alloys in longitudinal and transverse directions after hot extrusion at different temperatures 
The yield strength (YS) of the alloys vs extrusion temperature is shown in Figure $\mathbf{3 b}$. It can be seen that YS of alloys in transverse direction is almost the same for most of alloys (except MgZn2Ca0.5) and for all extrusion temperatures. The $Y S$ in longitudinal direction of alloys with $2 \mathrm{wt} \%$ of $\mathrm{Zn}$ (MgZn2Ca0.5 and MgZn2Ca0.5Mn1) were not affected by hot extrusion temperature. However, for alloys with $4 \mathrm{wt} \% \mathrm{Zn}$ (MgZn4Ca0.5 and MgZn4Ca0.5Mn1) at low extrusion temperatures the higher YS in longitudinal direction was observed. The difference of $Y S$ in longitudinal and transverse direction was lower than for UTS. The only exceptions were previously mentioned alloys with $4 \mathrm{wt} \%$ $\mathrm{Zn}$.

The elongation (EI) of the alloys vs extrusion temperature is shown in Figure 3c. First of all it should be said that high confidence interval for El is observed. In most cases the El in longitudinal direction is higher than in transverse direction. The highest elongation was demonstrated for $\mathrm{MgZn} 4 \mathrm{CaO} .5$ alloy at extrusion temperatures of 250 and $300{ }^{\circ} \mathrm{C}$. As for extrusion at low temperatures the El of that alloy is very high in longitudinal and low in transverse direction. The high elongation (>20\%) in both longitudinal and transverse directions is also observed for MgZn2Ca0.5 alloy, but only at extrusion temperature of $300^{\circ} \mathrm{C}$. It can be seen that $\mathrm{Mn}$ addition has detrimental effect on alloys elongation.

The mechanical properties of the same alloys after ECAP processing are following: YS $=80-100 \mathrm{MPa}$; UTS = 220-240 MPa and $\mathrm{El}=15-30 \%$ [8]. It can be seen that investigated alloys after hot extrusion have higher YS and UTS and near the same El in comparison with alloys after ECAP. However, the mechanical properties of alloys after ECAP are the same in longitudinal and transverse directions. As for hot extrusion, the properties are nearly the same in longitudinal and transverse directions at high extrusion temperatures only.

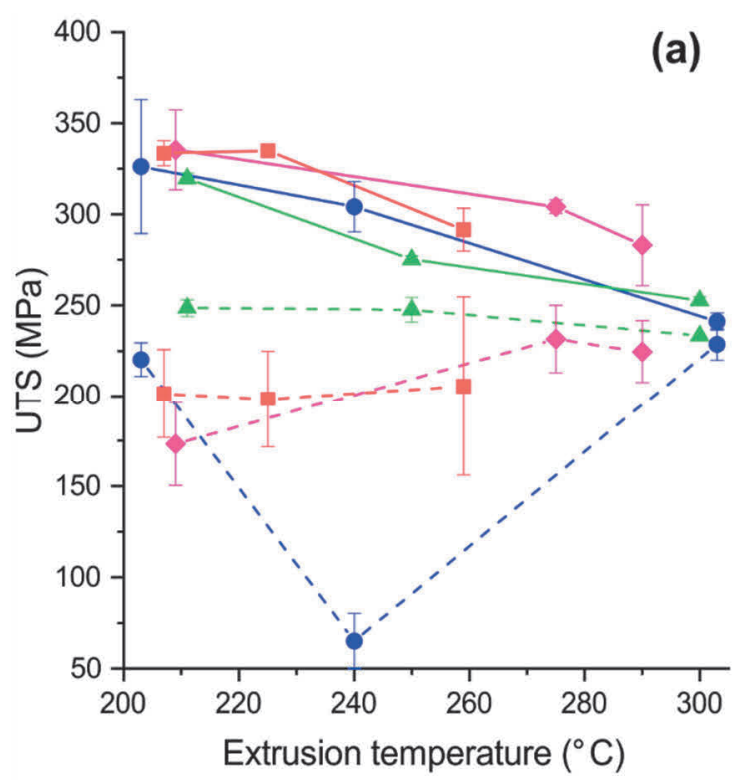



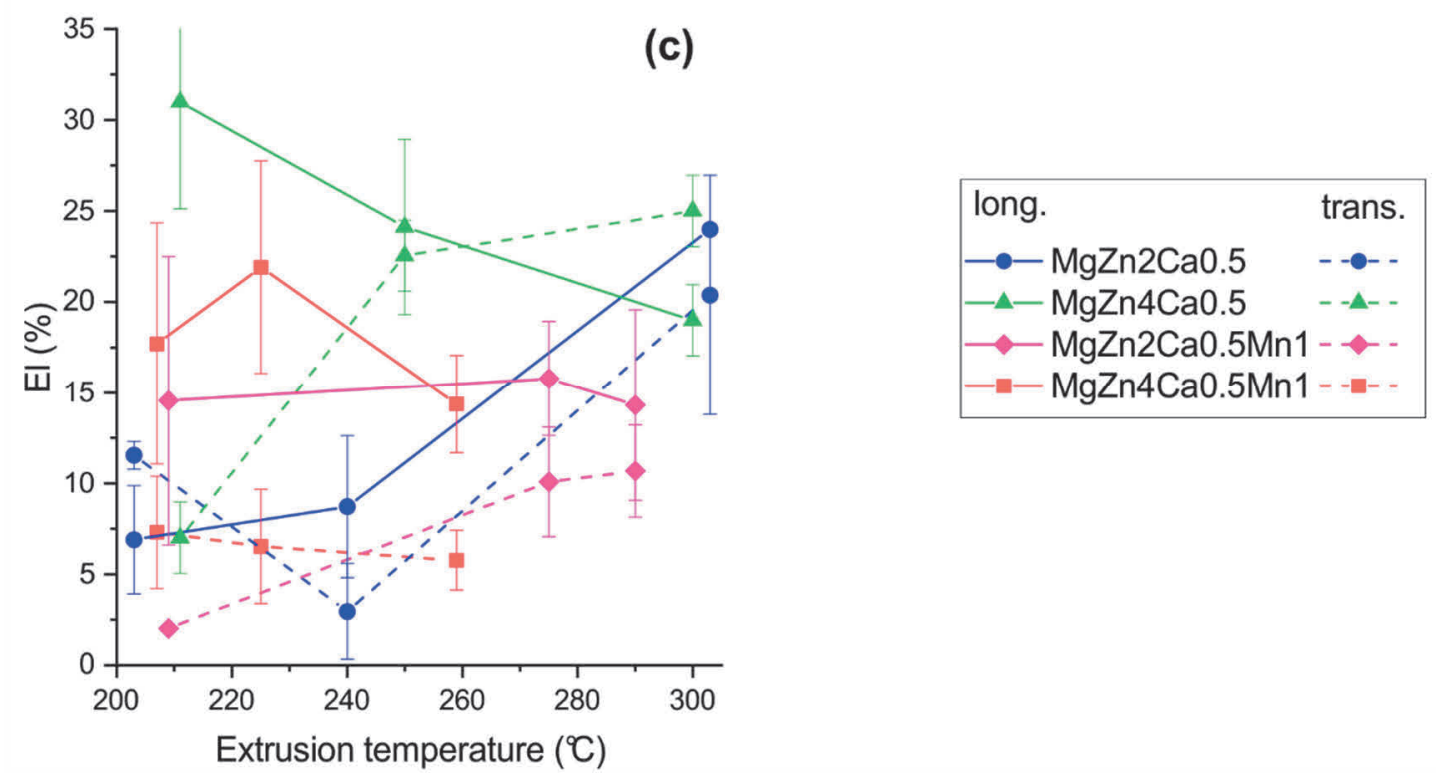

Figure 3 The mechanical properties of alloys after hot extrusion at different temperatures: (a) ultimate tensile strength (UTS); (b) yield strength (YS); (c) elongation (EI)

\section{CONCLUSION}

The influence of hot extrusion at different temperature on the microstructure and mechanical properties in longitudinal and transverse directions of Mg- $4 \% \mathrm{Zn}-0.5 \% \mathrm{Ca}, \mathrm{Mg}-2 \% \mathrm{Zn}-0.5 \% \mathrm{Ca}, \mathrm{Mg}-4 \% \mathrm{Zn}-0.5 \% \mathrm{Ca}-1 \% \mathrm{Mn}$ and $\mathrm{Mg}-2 \% \mathrm{Zn}-0.5 \% \mathrm{Ca}-1 \% \mathrm{Mn}$ (wt\%) alloys were Investigated. The alloys microstructures consist of (Mg) solid solution grains and $\mathrm{Ca}_{2} \mathrm{Mg}_{6} \mathrm{Zn}_{3}$ phase. At low hot extrusion temperatures, the large non-recrystallized elongated grains are observed. However, at high hot extrusion temperatures, the microstructure looks uniform and fully recrystallized. In most cases the grains are finer for low hot extrusion temperatures and grain size of extruded alloys changes from 1.5 to $6.2 \mu \mathrm{m}$. Only for MgZn4Ca0.5Mn1 alloy the near $3 \mu \mathrm{m}$ grains are observed at all extrusion temperatures. The mechanical properties are higher in longitudinal direction in comparison with transverse direction. As for tensile properties vs extrusion temperature, it shows that for lower extrusion temperatures high UTS, YS and low El of alloys are typical. The best combination of mechanical properties is observed for MgZn4Ca0.5 alloy. Mn addition promotes the low El and higher difference of mechanical properties in longitudinal and transverse directions.

\section{ACKNOWLEDGEMENTS}

The authors gratefully acknowledge the financial support of the Ministry of Science and Higher Education of the Russian Federation in the framework of Increase Competitiveness Program of NUST «MISiS» (№ K2-2019-008), implemented by a governmental decree dated 16th of March 2013, N 211.

\section{REFERENCES}

[1] RICHARDS, Andrew M., COLEMAN, Nathan W., KNIGHT, Trevor A., BELKOFF, Stephen M. and MAERS, Simon C. Bone density and cortical thickness in normal, osteopenic, and osteoporotic sacra. Journal of Osteoporosis. 2010. vol. 2010, ID 504078.

[2] STAIGER, Mark P., PIETAK, Alexis M., HUADMAI, Jerawala and DIAS, George. Magnesium and its alloys as orthopedic biomaterials: A review. Biomaterials. 2006. vol. 27, no. 9, pp. 1728-1734.

[3] SUN, Yu, ZHANG, Baoping, WANG, Yin, GENG, Lin and JIAO, Xiaohui. Preparation and characterization of a new biomedical Mg-Zn-Ca alloy. Materials \& Design. 2012. vol. 34, pp. 58-64. 
[4] ZHANG, Baoping, WANG, Yin, GENG, Lin and LU, Chunxiang. Effects of calcium on texture and mechanical properties of hot-extruded Mg-Zn-Ca alloys. Materials Science and Engineering: A. 2012. vol. 539, pp. 56-60.

[5] TONG, L.B., ZHENG, M.Y., HU, X.S., WU, K., XU, S.W., KAMADO, S. and KOJIMA, Y. Influence of ECAP routes on microstructure and mechanical properties of Mg-Zn-Ca alloy. Materials Science and Engineering: A. 2010. vol. 527, no. $16-17$, pp. 4250-4256.

[6] TONG, L.B., ZHENG, M.Y., XU, S.W., KAMADO, S., DU, Y.Z., HU, X.S., WU, K., GAN, W.M., BROKMEIER, H.G., WANG, G.J. and LV, X.Y. Effect of Mn addition on microstructure, texture and mechanical properties of MgZn-Ca alloy. Materials Science and Engineering: A. 2011. vol. 528, no. 10-11, pp. 3741-3747.

[7] GENG, L., ZHANG, B.P., LI, A.B. and DONG, C.C. Microstructure and mechanical properties of Mg-4.0Zn-0.5Ca alloy. Materials Letters. 2009. vol. 63, no. 5, pp. 557-559.

[8] KOLTYGIN, A., BAZHENOV, V., KOMISSAROV, A., KHASENOVA, R., ANISHCHENKO, A., FOZILOV, B., BAUTIN, V., SEFERYAN, A., BILYALOV, A. Effect of ECAP on the Microstructure, Mechanical and Corrosion Properties of Mg-Zn-Ca and Mg-Zn-Ca-Mn Biodegradable Alloys. In METAL 2018: 27th International Conference on Metallurgy and Materials. Ostrava: TANGER, 2018, pp. 1388-1393.

[9] CHO, Dae H., LEE, Byoung W., PARK, Jin Y., CHO, Kyung M. and PARK, Ik M. Effect of Mn addition on corrosion properties of biodegradable Mg-4Zn-0.5Ca-xMn alloys. Journal of Alloys and Compounds. 2017. vol. 695, pp. 1166-1174.

[10] CHO, Dae H., NAM, Ji H., LEE, Byoung W., CHO, Kyung M. and PARK, Ik M. Effect of Mn addition on grain refinement of biodegradable Mg-4Zn-0.5Ca alloy. Journal of Alloys and Compounds. 2016. vol. 676. pp. 461-468. 